\title{
Chaos Amid Chaos: Oxygen Lack in Manaus Hospitals during the Covid 19 Pandemic
}

\section{Azevedo $\mathrm{NH}^{*}$}

Master in Environmental Law, Amazonas State University, Brazil

*Corresponding author: Nilcinara Huerb de Azevedo, Master in Environmental Law from the Amazonas State University, Lawyer, Brazil, Email: nilci_azevedo@hotmail.com

\author{
Opinion \\ Volume 4 Issue 1 \\ Received Date: March 15, 2021 \\ Published Date: March 23, 2021 \\ DOI: $10.23880 /$ abca-16000170
}

\section{Opinion}

Considered one of the greatest tragedies of the current century, the Covid 19 pandemic in Brazil has been breaking depresseing records, which currently set/place it in second place in the ranking of countries most affected by the health crisis, behind only the USA.

Manaus, the first Brazilian city to record, in 2020, a collapse in the health and funeral system, was in 2021 once again scenery of one of the most terrifying episodes of the entire pandemic, which was strongly reflected in the international media. The lack of oxygen a basic supply in hospitals as well as electricity in modern life provocaded risk of death of newborn babies in maternity hospitals, it has led to the death of countless people, including an entire ward of patients at the University Hospital, and it has left many others with permanent brain damage, which has forced health professionals, in a complete state of exhaustion, to resort to manual ventilation as the only way to try to save as many lives as possible.

The city that used to have an average of 20 burials a day; in what was called the "second wave", it registered more than 200 burials in a single day. Besides the ICU cases, the humanitarian drama also extended to the family members themselves, who, in order to relieve the suffering of their loved ones, resorted to renting and buying oxygen cylinders, often having to face the danger of contamination due to the agglomeration in the kilometers-long lines that were formed at the door of the main supplier company.

Due to the lack of beds and supplies in hospitals, it has become quite common for people to die inside their homes or even choose not to be hospitalized, when possible, for fear of dying in dramatic conditions and far from their families. In the same way, due to the stress caused in the hospital units, which have become veritable war zones, patients have even taken flight as a way to try to escape from what seemed to be the only possible destiny, making police reinforcement essential at that moment given the lack of coordinated actions between the federal and state governments, the actions of celebrities, volunteers, and civil entities were primordial for the largest possible amount of raw material to be acquired, and thus be able to supply not only the capital but also the others cities in the state of Amazonas that had also been suffering from oxygen shortages.

Indeed, there were many factors that contributed to the installation of this unprecedented chaos, starting with the denialism of the federal government, which since the beginning of the pandemic has adopted a discourse completely opposite to that promoted by the World Health Organization and other international authorities, and that, therefore, ends up leading to socially inappropriate behavior. Added to this is the poor health management in the state, which promotes the scrapping of public hospitals and directly impacts the quality of the service provided. Likewise, the discovery of a new variant of the coronavirus found in the region, and which appears to have greater power of contagion, makes the situation even more serious.

According to studies, there is a high possibility that Manaus will face a "third wave" if there is no immediate paralysis of economic activities associated with a mass nonvaccination, and the same can be repeated in other regions of the country, considering that many states are already challenging the health system with all this, we can see that the pandemic context in Brazil, especially in the northern region, has brought to the surface problems that have long been faced, and that more than ever demand an immediate solution, among which we can cite: social inequality, domestic 
violence, mismanagement with public affairs, and the issue of neglect of the indigenous population.

Undoubtedly, the necropolitical and necroeconomic model currently in force in the country end up serving as obstacles to the fight against the pandemic, which makes it stronger and more damaging; thus, giving us the perception that besides needing to fight against this evil, it is essential to confront the system, so that only then, we can actually breathe. 